\title{
An Improved Hybrid Micro-Grid Load Frequency Control Scheme for an Autonomous System
}

\author{
${ }^{* 1}$ Ibrahim Abdulwahab, ${ }^{2}$ Shehu A. Faskari, ${ }^{2}$ Talatu A. Belgore and ${ }^{1}$ Taiwo A. Babaita \\ ${ }^{1}$ Department of Electrical Engineering, Ahmadu Bello University, Zaria, Nigeria \\ ${ }^{2}$ Department of Electrical and Computer Engineering, Baze University, Abuja, Nigeria \\ iabdulwahab@abu.edu.ng | anas.shehu@bazeuniversity.edu.ng | asiau.talatu@bazeuniversity.edu.ng | tbabaita@gmail.com
}

\author{
ORIGINAL RESEARCH ARTICLE \\ Received: 22-SEP-2021; Reviewed: 28-NOV-2021; Accepted: 13-DEC-2021 \\ http://dx.doi.org/10.46792/fuoyejet.v6i4.698
}

\begin{abstract}
This paper presents an improved hybrid micro-grid load frequency control scheme for an autonomous system. The micro-grid system comprises of renewable and non-renewable energy-based Power Generating Units (PGU) which consist of Solar Photovoltaic, WT Generator, Solar Thermal Power Generator, Diesel Engine Generator, Fuel Cell (FC) with Aqua Electrolizer (AE). However, power produce from renewable sources in microgrid are intermittent in supply, hence make it difficult to maintain power balance between generated power and demand. Therefore, Battery energy storage system, ultra-capacitor and flywheel energy storage systems make up the energy storage units. These separate units are selected and combined to form two different scenarios in this study. This approach mitigates frequency fluctuations during disturbances (sudden load changes) by ensuring balance between the generated power and demand. For each scenario, Moth flame optimization algorithm optimized Proportional-Integral controllers were utilized to control the micro-grid (to minimize fluctuations from the output power of the non-dispatchable sources and from sudden load change). The results of the developed scheme were compared with that of Quasi-Oppositional Harmony Search Algorithm for overshoot and settling time of the frequency deviation. From the results obtained, the proposed scheme outperformed that of the quasi-oppositional harmony search algorithm optimized controller by an average percentage improvement of $35.95 \%$ and $28.76 \%$ in the case of overshoot and settling time when the system step input was suddenly increased. All modelling analysis were carried out in MATLAB R2019b environment.
\end{abstract}

Keywords-Frequency Deviation, Micro-grid, Moth flame optimization algorithm, Quasi-Oppositional Harmony Search Algorithm.

\section{INTRODUCTION}

Elections lectrical power generated or consumed in a country plays significant role on the level of development of that country (Abdulwahab et al., 2020; Shankar \& Mukherjee 2016). Due to continuous increase in the price of fuel and growing concerns over global climate change, countries are deploying alternative means of generating electricity (Abdulwahab et al., 2021; Abubakar et al., 2019; Jibril et al., 2019). Renewable energy sources (RES) include: wind, solar, biomass, bio-fuel and geothermal energy (Wang et al., 2016). Electricity generated from RES is now preferred due to fossil-fuel resources depletion and rising concern about $\mathrm{CO} 2$ emissions which causes global warming (Einan et al., 2017).

Greater attention is now focused on wind and solar sources due to the various advantages it has over the other RES (Shehu et al., 2019). For increasing the reliability of energy generated, the WT system and the photovoltaic system are used together in isolated systems (Shankar \& Mukherjee 2016). The power generated by the WT generators and solar PV generators, on the other hand, is irregular. Energy storage systems are important for ensuring balance in isolated systems' generation and consumption by storing and releasing suitable amounts of electricity as needed. (Einan et al., 2017). Storage devices are incorporated into the microgrid system to compensate for the fluctuations of the output power from the generators due to unfavorable weather conditions (Einan et al., 2017).

\section{*Corresponding Author}

Section B- ELECTRICAL/ COMPUTER ENGINEERING \& RELATED SCIENCES Can be cited as:

Abdulwahab I., Faskari S.A., Belgore T.A., and Babaita T.A. (2021): An Improved Hybrid Micro-Grid Load Frequency Control Scheme for an Autonomous System FUOYE Journal of Engineering and Technology (FUOYEJET), 6(4), 369-374. http://dx.doi.org/10.46792/fuoyejet.v6i4.698
However, because generator output power varies constantly, adding energy storage devices will only reduce the disparity between the power supplied and the load demand. Due to the difference in power, the frequency deviates from its nominal value during unexpected changes in the load connected to the microgrid. (Abdulwahab et al., 2020). However, for a healthy microgrid system to operate, both frequency and tie-line power planned values must be kept within an acceptable range, as changes in frequency value would result in a real power imbalance in the system. (Hanwate \& Hote 2018). As a result, power system control and management are prominent study area.

The major goal of this research is to maintain balance between the electrical power generated by the microgrid and reduce frequency deviation caused by generator power variations and unexpected increases or decreases in load (Teresa \& Krishnarayalu). In order to control the power in a microgrid system, several approaches have been presented by researchers. These approaches include adding energy storage devices to the microgrid to supply power during unbalanced configurations, and using a fuzzy logic controller to regulate the microgrid output. (Sukumar et al., 2017) and the use of PID controller to individually control the distributed generators. Among all the techniques used, the use of PID controller is widely used due to its ability in ensuring proper control of the generators. furthermore, to mitigate disturbances, the PID and power sharing controller parameters were carefully selected to promote the system performance (Shankar \& Mukherjee 2016).

In line with the problems identified, researchers have used various methods for the selection of the parameters of the PID controller. However, these methods require a lot of computational time. Lately meta-heuristic 
techniques have been used to optimize the PID controllers of the generators (Razavi et al., 2012; Kai Yu et al., 2016). However it has been seen that recent meta-heuristic techniques are now popularly been used for optimization in order to ensure that the power generated from the microgrid are balanced with the demand giving efficient optimal solution to the problems related to control and operation of an autonomous hybrid power system model (HPSM) (Shankar \& Mukherjee 2016). To minimize the frequency deviation that is caused as a result of continuous change in load, this research work developed the use of moth-flame optimization control scheme to optimize the controllers of the generators individually due to its enhanced fine-tuning characteristic and faster convergence rate of moth-flame optimization algorithm. This ensures that there is balance between the power generated and that needed by the consumers.

\section{RELATED WORK}

Sukumar et al. (2017) developed a power management system for a grid connected PV and solid oxide fuel cell (SOFC), considering variation in the load and solar radiation. The main aim of the work was to develop hybrid distributed energy resources (PV and SOFC) that will ensure balance between the power supplied by the generators and the load demand from the consumers without any input from the grid system. The results obtained from the proposed model showed that, with the help of the controller, the output power from the fuel cell was able to match its reference value. The work is limited by weak performance criteria.

(Dongmin Yu et al., 2019) proposed and presented a dynamic multi agent-based management and load frequency control of PV/Fuel cell/ wind turbine/ CHP in autonomous microgrid system. The work centred to control the frequency oscillation of each agent and minimize the production cost of the whole interconnected system. The result was remarkable however, the controller operates only when the load is reduced. (Veronica et al., 2020) presented a work on load frequency control (LFC) scheme for the distributed generation (DG) system of the microgrid using the D-partition method (DPM). Simulation results demonstrate the robustness of the DPM, which is superior in damping frequency oscillations of microgrid in small load only.

\section{Methodology}

Several micro-resources (renewable and non-renewable) of power generation units (PGU) and energy storage units (ESU) are integrated to form the proposed HPSM which in turn makes an isolated microgrid. For practicable simulation, these power generators are grouped into two different possible scenarios then, the schematic, data and parameters as used in the work of (Shankar \& Mukherjee 2016) were adopted. It is worthy to note that the power generation $\left(P_{-} G\right)$ is a function of the PGUs output power such as Diesel engine generator, wind turbine generator, solar power generator, solar thermal power generator and fuel cell, with the AE absorbed power and the power exchange from ESUs like UC, FESS and BESS which is described as in Eq. (1). The sign $( \pm)$ shows the power generation and absorption capacities of the ESU.

$$
\begin{aligned}
\mathrm{P}_{\mathrm{G}}=\mathrm{P}_{\mathrm{WTG}}+\mathrm{P}_{\mathrm{SPG}} & +\mathrm{P}_{\mathrm{STPG}}+\mathrm{P}_{\mathrm{DEG}}+\mathrm{P}_{\mathrm{FC}}-\mathrm{P}_{A E} \pm \mathrm{P}_{\mathrm{BESS}} \\
& \pm \mathrm{P}_{\mathrm{FESS}} \pm \mathrm{P}_{\mathrm{UC}}
\end{aligned}
$$

For the first scenario, the microgrid comprises of wind turbine (WT) generator, solar thermal power generator (STPG) and Diesel Engine Generator (DEG). Others are FC with AE and the battery energy storage system (BESS) for energy storage. PWTG and PSTPG input power values were set to 0.5 p.u and 0.36 p.u respectively for the first 40 seconds of the simulation. Thereafter, this values for PWTG and PSTPG were decreased to 0.4p.u and 0.18p.u respectively while the load, PL was kept constant at 1.0p.u. After 80 seconds, the load PL was increased to 1.1p.u up till the end of the simulation. The total time of simulation is 120 seconds and overall value for the total power generated, $P G$ for this microgrid is expressed as:

$$
\mathrm{P}_{\mathrm{G}}=\mathrm{P}_{\mathrm{WTG}}+\mathrm{P}_{\mathrm{STPG}}+\mathrm{P}_{\mathrm{DEG}}+\mathrm{P}_{\mathrm{FC}}-\mathrm{P}_{A E} \pm \mathrm{P}_{\mathrm{BESS}}
$$

In the second Scenario, the microgrid is the same with that of the first scenario 1 except that the simulation was ran for 400 seconds and the modelling values for the WTG, STPG and load demand, PL were stochastic data incorporated randomly. In this work, the settling time, overshoot and undershoot of the frequency deviation curve are taking as performance metrics. The values for the frequency will be ascertain from the frequency deviation plot with time when there is sudden change of load and generators power fluctuations.

\section{Results AND Discussion 4.1 Variation of Power Generation OUtPut and LOAD DEMAND FOR SCENARIO-1 SIMULATION}

The result below is the simulation output curve for variation in the load demand and power generation, the power sharing profiles of the system and the frequency deviation curve of the system. Figure 1(a) shows the plot of load demand, PL against Time (s). During the simulation, the load demand was set to 1.0p.u from the beginning of the simulation and increased to 1.1 p.u at the 80 th seconds. Figure $1(\mathrm{~b})$ and $1(\mathrm{c})$ show the nondispatchable sources output, PWTG and PSTPG. Output power values were set to $0.5 \mathrm{p} . \mathrm{u}$ and $0.36 \mathrm{p} . \mathrm{u}$ respectively for the first 40 seconds of the simulation time. Thereafter, this values for PWTG and PSTPG were decreased to 0.4 p.u and 0.18p.u respectively till the end of the 120 seconds simulation.

Figures 2(a), (b), (c) and (d) show plots of the scheme controlled DEG, FC, AE and BESS Power Output values in p.u against Time (s). The connected dispatchable generators in this power sources act accordingly with their integrated PID controllers to mitigate the power mismatch initiated by the varying output values of the non-dispatchable power sources in Figure 1 to supply the required power to the connected load, hence eradicating the frequency deviation, $\Delta \mathrm{F}$ from initiated perturbations. These coordinated performances are obtained by the MFOA tuned PID controllers incorporated to the generators in the studied scenario with the discussed simulated perturbations at the 40th and 80th seconds of the simulation time. The optimal values of the PID controller's gains in this scenario are presented in Table 1 and compared with that of QOHSA in literature. 

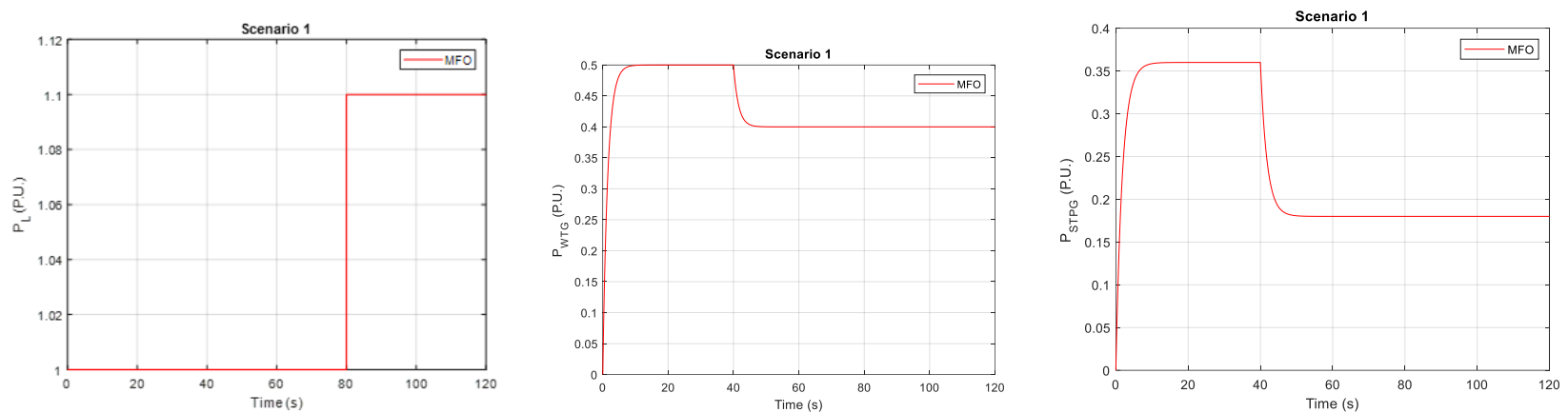

Fig. 1 (a): Load Demand Against Time, (b) \& (c): Non-Dispatchable Outputs

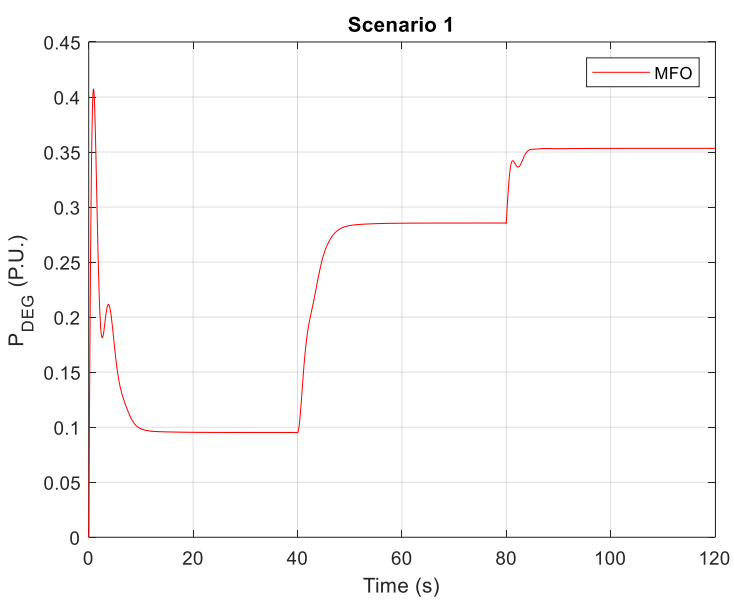

(a)

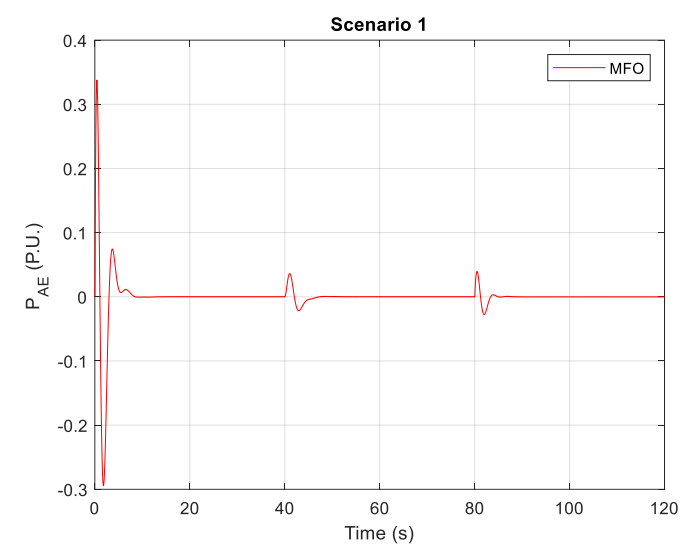

(c)

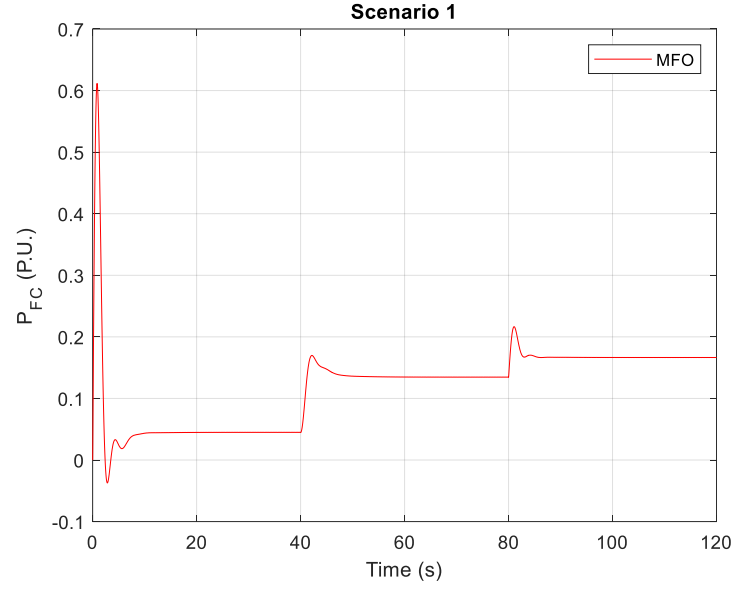

(b)

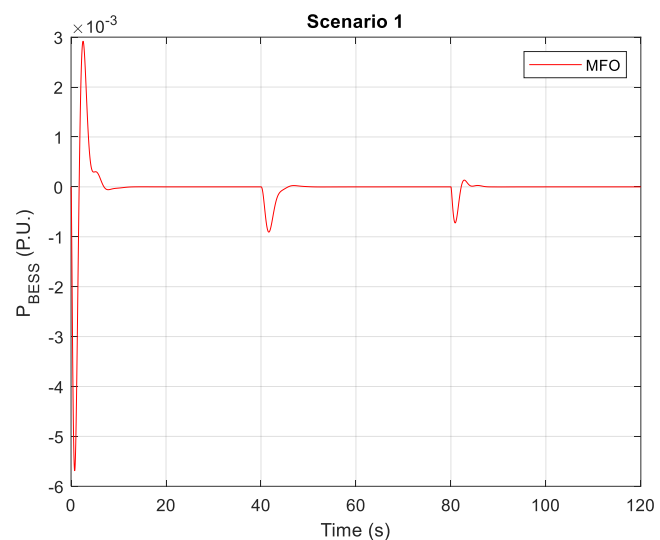

(d)

Fig. 2: Power responses of DEG, FC, AE and BESS for scenario 1

Table 1. Optimized Controller Gain values for Scenario 1

\begin{tabular}{|c|c|c|c|c|c|c|c|c|c|}
\hline \multirow{3}{*}{$\begin{array}{l}\text { Controller- } \\
\text { Algorithm }\end{array}$} & \multicolumn{9}{|c|}{ Controllers for PGU } \\
\hline & \multicolumn{3}{|c|}{ Controller_DEG } & \multicolumn{3}{|c|}{ Controller_FC } & \multicolumn{3}{|c|}{ Controller_DEG } \\
\hline & $\mathrm{Kp}$ & $\mathrm{Ki}$ & $\mathrm{Kd}$ & $\mathrm{Kp}$ & $\mathrm{Ki}$ & $\mathrm{Kd}$ & $\mathrm{Kp}$ & $\mathrm{Ki}$ & $\mathrm{Kd}$ \\
\hline PID-QOHSA & 92.477 & 38.212 & 94.795 & 4.496 & 1.422 & 4.564 & 0.0741 & 0.0435 & 0.0435 \\
\hline PID-MFOA & 99.999 & 99.998 & 100.00 & 100.00 & 15.710 & 100.00 & 0.0001 & 0.0001 & 87.587 \\
\hline
\end{tabular}




\subsection{VARIation of PoWer Generation OUtPut AND LOAD DEMAND FOR SCENARIO-2 SIMULATION}

A randomly varying power output models from a practical WTG and STPG together with the accompanied stochastic load demand model, PL used during the scenario 2 simulation process were used as depicted in Figure 3. Figures 3 (a), (b) and (c) are the simulation curves for the stochastic practical load model, PL the variation of power output generation curve from WTG and SPTG respectively from the simulation of scenario 2 autonomous hybrid microgrid model. The load demand for this scenario is of randomly varying output as well as the output power from the non-dispatchable power sources, PWTG and PSTPG as shown in Figure 3(b) and
$3 c$ respectively. The expended time of simulation for this scenario is 400 seconds.

Figure $4(\mathrm{a}, \mathrm{b}, \mathrm{C}$, and d) display the scheme controlled DEG, FC, AE and BESS power output values in p.u against simulation time (s). The connected generators with the response above act accordingly with their integrated PID controllers to alleviates power mismatch by supplying the needed values of generated power to the connected stochastic load model and non-dispatchable power sources output from Figure 4 in eliminating power mismatch to reduce deviation of frequency, $\Delta \mathrm{F}$ to zero. These coordinated performances are obtained by the MFOA tuned PID controllers incorporated to the generators in the studied scenario. The optimal values of the PID controller's gains in this scenario are presented in Table 2 and compared with that of QOHSA in literature.

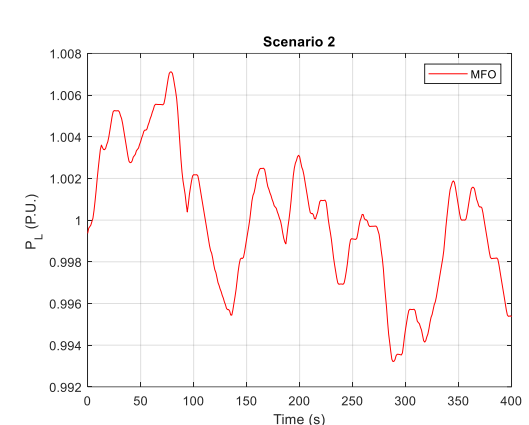

(a)

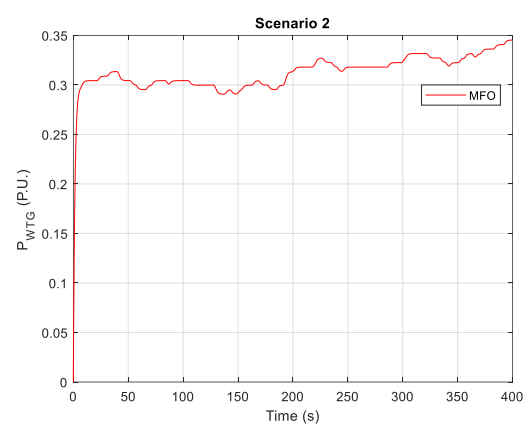

(b)

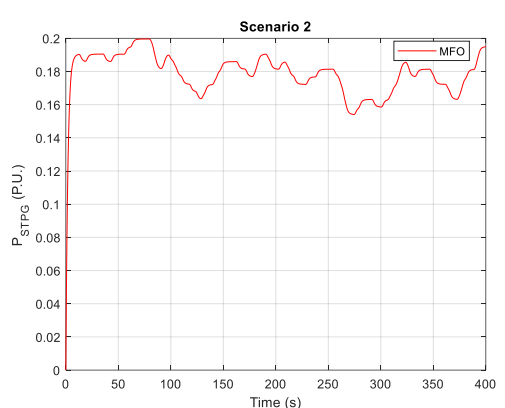

(c)

Fig. 3(a-c): Variation of power generation and load demand for scenario 2

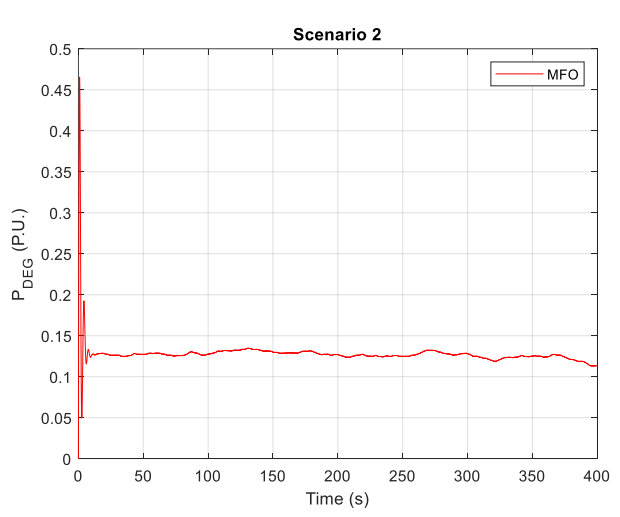

(a)

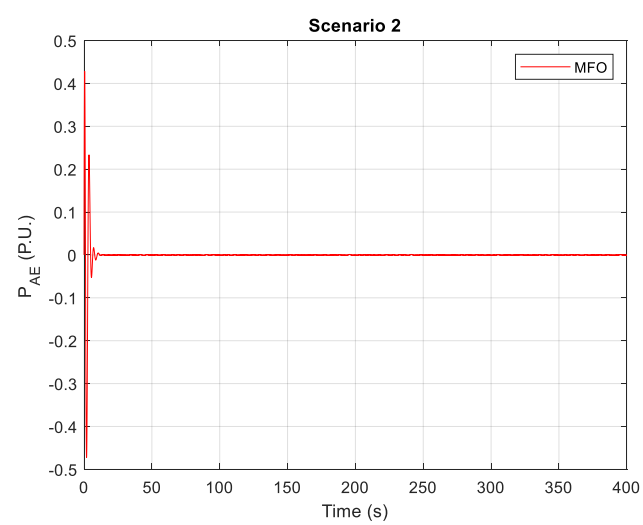

(c)

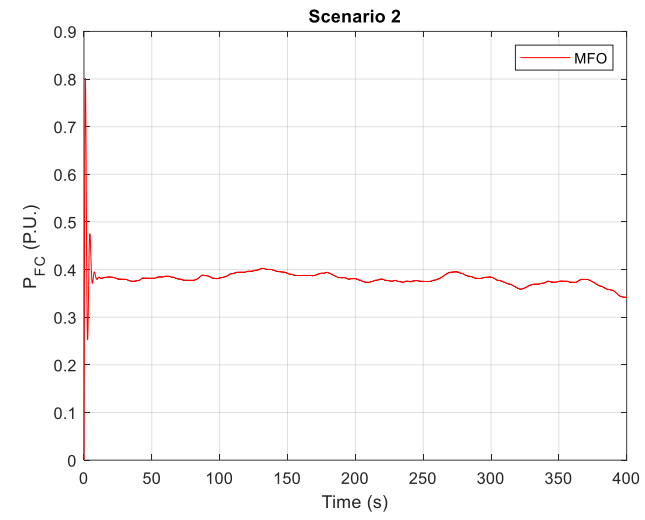

(b)

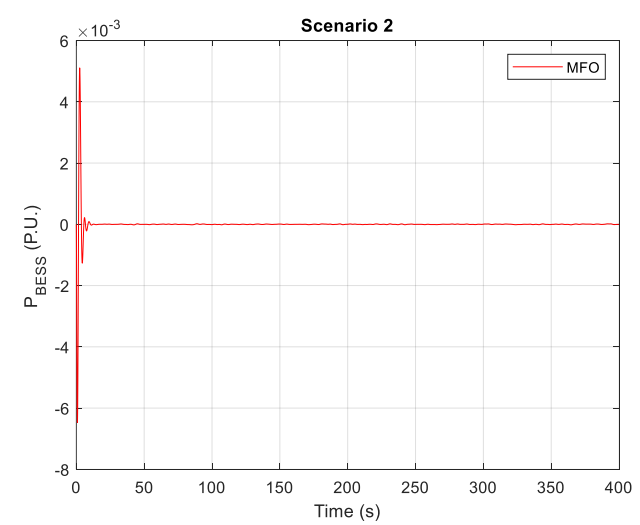

(d)

Fig. 4 (a-d): Power response of DEG, FC, AE and BESS for scenario 2 


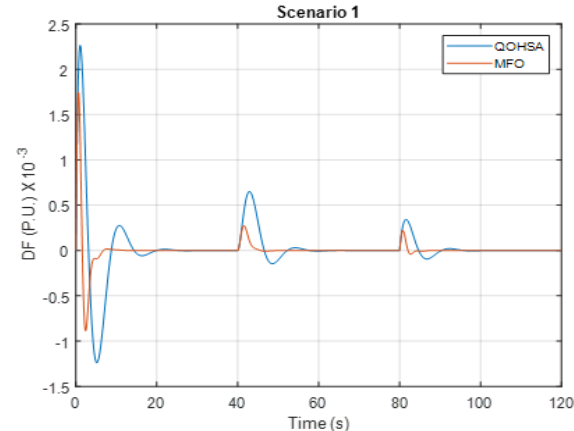

(a)

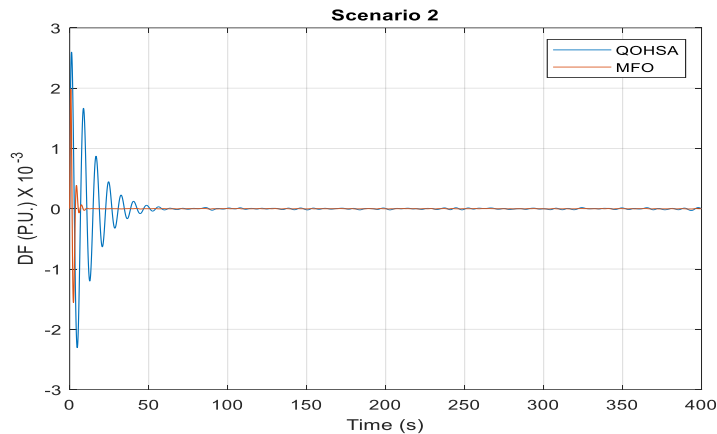

(b)

Fig. 5: Comparative frequency deviation of QOHSA and MFOA of PID controlled autonomous HPSM for scenario 1 and scenario 2

Table 2. Optimized Controller Gain values for Scenario 2

\begin{tabular}{|c|c|c|c|c|c|c|c|c|c|}
\hline \multirow{3}{*}{$\begin{array}{l}\text { Controller- } \\
\text { Algorithm }\end{array}$} & \multicolumn{9}{|c|}{ Controllers for PGU } \\
\hline & \multicolumn{3}{|c|}{ Controller DEG } & \multicolumn{3}{|c|}{ Controller FC } & \multicolumn{3}{|c|}{ Controller DEG } \\
\hline & $\mathrm{Kp}$ & $\mathrm{Ki}$ & $\mathrm{Kd}$ & $\mathrm{Kp}$ & $\mathrm{Ki}$ & $\mathrm{Kd}$ & $\mathrm{Kp}$ & $\mathrm{Ki}$ & $\mathrm{Kd}$ \\
\hline PID-QOHSA & 95.468 & 93.724 & 98.118 & 0.169 & 1.564 & 2.593 & 0.0985 & 0.0872 & 0.0342 \\
\hline PID-MFOA & 100.00 & 100.00 & 100.00 & 100.00 & 100.00 & 100 & 0.0001 & 0.0001 & 100.00 \\
\hline
\end{tabular}

Table 3. Performance metrics for the MFOA and QOHSA optimized PID controlled HPSM for Scenario 1

\begin{tabular}{|c|c|c|c|c|c|c|c|c|c|}
\hline \multirow{2}{*}{ Algorithm } & \multicolumn{3}{|c|}{ Settling Time (s) } & \multicolumn{3}{|c|}{ Peak Overshoot $(\mathrm{Hz})$} & \multicolumn{3}{|c|}{ Peak Undershoot $(\mathrm{Hz})$} \\
\hline & 0s & $40 \mathrm{~s}$ & $80 \mathrm{~s}$ & 0s & $40 \mathrm{~s}$ & $80 \mathrm{~s}$ & 0s & $40 \mathrm{~s}$ & $80 s$ \\
\hline PID-QOHSA & 31.1 & 68.07 & 105.17 & 2.26 & 0.65 & 0.34 & 1.24 & -0.1 & -0.09 \\
\hline PID-MFOA & 12.94 & 51.53 & 87.48 & 1.74 & 0.27 & 0.22 & 0.89 & -0.01 & -0.04 \\
\hline \% Improvement & $58.39 \%$ & $24.30 \%$ & $16.82 \%$ & $23.01 \%$ & $58.46 \%$ & $35.29 \%$ & $28.23 \%$ & $90.00 \%$ & $55.56 \%$ \\
\hline $\begin{array}{c}\text { Avr. \% } \\
\text { Improvement }\end{array}$ & & $33.17 \%$ & & & $38.92 \%$ & & & $7.93 \%$ & \\
\hline
\end{tabular}

Table 4. Performance metrics for the MFOA and QOHSA optimized PID controlled HPSM for Scenario 2

\begin{tabular}{l|c|c}
\hline \multirow{2}{*}{ Algorithm } & Peak Overshoot (Hz) & Peak Undershoot(Hz) \\
\cline { 2 - 3 } & $0 \mathrm{~s}$ & $0 \mathrm{~s}$ \\
\hline PID-QOHSA & 2.60 & -2.30 \\
\hline PID-MFOA & 1.98 & -1.55 \\
\hline$\%$ Improvement & $\mathbf{2 3 . 8 5 \%}$ & $\mathbf{3 2 . 6 1 \%}$ \\
\hline
\end{tabular}

The comparative values of settling time, overshoot and undershoot from the frequency deviation curves that arises due to system perturbations in the two simulated autonomous hybrid power system scenarios are discussed. From the comparative QOHSA and MFOA response graph in Figure 5a, MFOA offers better transient performance in terms of settling time, minimum overshoot and undershoot in comparison to the QOHSA counterpart for the same scenario of autonomous HPSM as seen in literature. Table 3 shows the comparative values of these metrics for the three perturbation instances generated during the simulation process for the studied scenario 1.

Figure $5 \mathrm{~b}$ shows the comparative QOHSA and MFOA response graph for scenario 2 under stochastic load and power change, it can be seen that MFOA offers better transient performance with faster settling time and less oscillations compared to the QOHSA control scheme for the same scenario of autonomous HPSM. Table 4 clearly shows the comparative performance values that indicates the superiority of the MFOA over QOHSA control scheme as applied through the same simulation process for the studied scenario. Table 4 shows Scenario 2 comparative values of performance metrics for the MFOA and QOHSA optimized PID controlled HPSM

\section{ConClusion}

An improved Load Frequency Control (LFC) scheme using Moth Flame Optimization Algorithm (MFOA) optimized Proportional-Integral controllers has been presented in order to mitigate frequency deviation by providing a coordinated power generation - load demand balance in an autonomous hybrid microgrids. Simulation models of different power generators combination that forms the two separate scenarios of autonomous hybrid micro-grid power system using MATLAB/Simulink 2019b environment was adopted in this study and the performance metric was limited to the improvement in system's response values of the frequency plot's undershoot, and overshoot. The superiority of the scheme was established as the simulation results shows better damping and power balance performance with clear percentage improvement of 35.95\% and $28.76 \%$ in the case of overshoot and settling time when the system step input was suddenly increased for the step input scenarios. 


\section{REFERENCES}

Abdulwahab, I., Jibril, Y., Olarinoye, G. A., Abubakar, A. S., Olaniyan, A. A., \& Mohammed, M. (2021). A Cuckoo Search Optimized Control of Dual Stator Induction Generator in Wind Energy Conversion System. 2nd International Conference / Training Workshop on Electrical Power Engineering (ICEPENG 2021), University of Nigeria, NSUKKA, Nigeria

Abdulwahab, I., Yusuf J. \& Olaniyan, A. A (2018). A Modified Droop Controller For Micro-Grid Power Quality Improvement Using Artificial Fish Swarm Algorithm. FUTA Journal of Engineering and Engineering Technology, 12(2), 253-259.

Abubakar, A. S., Olaniyan, A. A., Ibrahim, A., \& Sulaiman, S. H. (2019). An Improved Analytical Method For Optimal Sizing And Placement Of Power Electronic Based Distributed Generation Considering Harmonic Limits. Paper presented at the 2019 IEEE PES/IAS PowerAfrica 122-127.

Einan, M., Torkaman, H., \& Pourgholi, M. (2017). Optimized fuzzycuckoo controller for active power control of battery energy storage system, photovoltaic, fuel cell and wind turbine in an isolated micro-grid. Batteries, 3(3), 23.

Hanwate, S. D., \& Hote, Y. V. (2018). Optimal PID design for Load frequency control using QRAWCP approach. IFACPapersOnLine, 51(4), 651-656.

Jibril, Y., Olarinoye, G., Abubakar, A., Abdulwahab, I., \& Ajayi, O. (2019). Control Methods Used In Wind Energy Conversion System: A Review. ATBU Journal of Science, Technology and Education, 7(2), 53-59.

Kharrich, M., Akherraz, M., \& Sayouti, Y. (2017). Optimal sizing and cost of a Microgrid based in PV, WIND and BESS for a School of Engineering. Paper presented at the 2017 International Conference on Wireless Technologies, Embedded and Intelligent Systems (WITS) 1-5.

Razavi, F., Torani, R., Askarian, I., Asgharizadeh, A., \& Masoomi, N. (2012). Optimal design of islanded microgrid using genetic algorithm. Paper presented at the International Conference on Genetic and Evolutionary Methods (GEM'12)

Shankar, G., \& Mukherjee, V. (2016). Load frequency control of an autonomous hybrid power system by quasi-oppositional harmony search algorithm. International Journal of Electrical Power \& Energy Systems, 78, 715-734.

Shehu, A., Abubakar, A., Musayyibi, S., \& Idris, K. (2019). Doubly fed induction generator based wind energy conversion system: A Review. ATBU Journal of Science, Technology and Education, 7(3), 145-150.

Sukumar, S., Marsadek, M., Ramasamy, A., Mokhlis, H., \& Mekhilef, S. (2017). A fuzzy-based PI controller for power management of a grid-connected PV-SOFC hybrid system. Energies, 10(11), 1720.

Teresa, D., \& Krishnarayalu, M. On deregulated power system AGC with solar power. Int J Comput Appl, 975, 8887.

Veronica, A. J., Kumar, N. S., \& Gonzalez-Longatt, F. (2020). Design of load frequency control for a microgrid using D-partition method. International Journal of Emerging Electric Power Systems, 21(1).

Wang, S., Ge, L., Wang, K., \& Cai, S. (2016). Energy Management and Economic Operation Optimization of Microgrid under Uncertainty Energy Management of Distributed Generation Systems: InTech.

Yu, D., Zhu, H., Han, W., \& Holburn, D. (2019). Dynamic multi agent-based management and load frequency control of PV/fuel cell/wind turbine/CHP in autonomous microgrid system. Energy, 173, 554-568.

Yu, K., Ai, Q., Wang, S., Ni, J., \& Lv, T. (2016). Analysis and Optimization of Droop Controller for Microgrid System Based on Small-Signal Dynamic Model. IEEE Transactions on Smart Grid, vol. 7, no. 2, pp. 695-705 